\title{
ПРАВОВОЕ РЕГУЛИРОВАНИЕ ИНВЕСТИЦИЙ В ЭНЕРГЕТИЧЕСКИЙ СЕКТОР СТРАН СЕВЕРНОЙ АМЕРИКИ
}

Аннотация: В статье рассмотрены вопросы правового регулирования инвестиций в энергетический сектор США, Канады и Мексики. Проведенный анализ показал, что несмотря на географическую близость этих трех стран и их сотрудничество в рамках Североамериканской зоны свободной торговли (НАФТА), регулирование инвестииий, в том числе и иностранных инвестиций происходит поразному. Так, например, в Канаде уровень инвестииий в этот сектор достаточно высок. Инвестирование в канадскую энергетику стимулируется как государством, так и провинциями, при этом приоритетным направлением таких мер являются возобновляемые источники энергии. Энергетические рынки США практически полностью либерализованы, т.е. находятся в частной собственности, что является одним из отличий от мексиканской и канадской отрасли энергетики. В то же время в Мексике ситуация обратная. Нефтегазовый сектор Мексики практически полностью принадлежит государству, а в Конституции этого государства установлено, что «...предоставление концессий на нефть и другие твердые, жидкие и газообразные углеводороды не допускается», что обуславливает достаточно низкий уровень инвестиций.

Review: The article is devoted to the questions of legal regulation of investments in the energy sector of the USA, Canada and Mexico. The results of the analysis showed that despite geographical proximity of these three countries and their cooperation within the North American Free Trade Agreement (NAFTA), these countries perform regulation of investments including foreign investments differently. For example, in Canada the level of investments in this sector is rather high. Investment in the Canadian energy industry is encouraged both at the state level and at the level of provinces, renewable energy resources being the priority of such measures. The energy markets of the USA are almost completely liberalized, i.e. are in private property that is one of differences from the Mexican and Canadian energy industry. At the same time the situation is just the opposite in Mexico. The oil and gas sector of Mexico almost completely belongs to the government and the Constitution of this State establishes that "concessions on oil and other solid, liquid and gaseous hydrocarbons are not allowed" which causes a rather low level of investments.

Ключевые слова: инвестиции, энергетика, США, Канада, Мексика, форма собственности, национальная политика, иностранные инвестииии, льготное налогообложение, либерализация.

Keywords: investments, energy industry, USA, Canada, Mexico, type of ownership, national policy, foreign investments, concessional taxation, liberalization.

\section{Канада}

Л иберализация и приватизация канадских энергетических мощностей является уже состоявшимся фактом в конце двадцатого века. Так, в Канаде не существует федеральной государственной энергетической структуры-корпорации или компании, а государство ограничивается лишь регулирующими функциями.

В то же время, на уровне провинций и даже местной власти, все еще действуют энергетические компании с публичным капиталом, которые в тоже время (практически в половине провинций) уже не являются вертикально интегрированными кор- порациями. Доминирующее участие государственного капитала в энергетических корпорациях остается в тех провинциях, где такие корпорации не были приватизированы, что позволяет сделать вывод, что сегодня канадские электроэнергетические компании функционируют в различных формах собственности. Так из 16 крупнейших канадских электроэнергетических компаний 8 принадлежат правительствам провинций, в 7 компаниях преобладает участие частного капитала, 2 компании принадлежат муниципалитетам. Среди компаний электроэнергетического комплекса среднего звена действуют и так называемые «территориальные коронные корпорации» (2 компании) (Crown 


\section{Политика и общество 4 (112) • 2014}

Corporations) $)^{1}$, а также несколько частных компаний провинции Онтарио.

Тем не менее, стоит отметить, что частные и мелкие муниципальные электроэнергетические компании, которых на современном этапе насчитывается около 400 (более $80 \%$ из них находится в Онтарио), производят незначительное количество энергии по сравнению с компаниями, в которых преобладает государственный капитал².

Инвестирование в канадский энергетический сектор находится на высоком уровне, что, в первую очередь, обусловлено интеграционными процессами в североамериканском регионе. Под воздействием таких процессов Канада либерализовала свои энергетические рынки и открыла их для зарубежного капитала.

Канадское законодательство допускает зарубежных инвесторов не только с частным капиталом, но и компании, в которых существует частичное или даже доминирующее участие зарубежных государственных (или квазигосударственных) структур (зарубежных государственных корпораций). В связи с этим Канада стала одним из мировых лидеров по объему зарубежных инвестиций в энергетику. Прямые зарубежные инвестиции в энергетику в 2010 г. составили 193 млрд. долларов ${ }^{3}$.

Основным актом в сфере правового регулирования инвестиций в Канаде является Канадский закон об инвестициия (Loi sur Investissement Canada) ${ }^{4}$. Закон применяется и в отношении зарубежных инвестиций, которые, тем не менее, рассматриваются в законе как потенциально угрожающие безопасности государства (см. часть 4 закона, ст. 25 и сл.), что требует контроля со стороны принимающего государства. В целях осуществления

\footnotetext{
${ }^{1}$ Речь идет о компаниях с государственным капиталом (чаще всего капиталом провинций), к которым применяются правила функционирования частных независимых корпораций. В отношении таких компаний не существует бюджетного (государственного) контроля, а также прямого административного контроля со стороны правительства или Парламента. См. Crown Corporation, in The Canadian Encyclopedia, 2013, http://www. thecanadianencyclopedia.com/articles/crown-corporation

${ }^{2}$ F. P. Sioshansi, W. Pfaffenberger, Electricity Market Reform: An International Perspective, Elsevier, 2006. - 688 p.

${ }^{3}$ Foreign Affairs and International Trade Canada, Trade and Economic Statistics (2010)

${ }^{4}$ Loi sur Investissement Canada (L.R.C. (1985), ch. 28 ( $1^{\mathrm{er}}$ suppl.))
}

такого контроля в Канаде было учреждено специальное подразделение по контролю за зарубежными инвестициями (Industry Canada's Investment Review Division - Управление по контролю инвестиций в канадской промышленности), которое находится под непосредственным руководством федерального министра промышленности Канады. В задачи управления входит анализ является ли участие определенного иностранного инвестора выгодным для Канады. Принимая решение о допуске того или иного инвестора федеральный министр промышленности руководствуется рекомендациями специального подразделения, а также такими факторами как:

- влияние тех или иных инвестиций на экономику страны (региона), трудовую занятость;

- наличие энергетических ресурсов в стране;

- предназначение энергетических услуг и продукции для внутреннем рынка Канады;

- принимает во внимание уровень участия в производстве представителей канадского энергетического сектора;

- и, наконец, рассматривает влияние данной инвестиции на развитие производительности, энергоэффективности, а также технического развития и инноваций в Канаде $)^{5}$.

В 2009 г. федеральным правительством были разработаны правила и процедуры контроля иностранных инвестиций в канадскую промышленность и канадскую энергетику - Регламент о потенцииально опасных для государственной безопасности инвестициях $x^{6}$. Данный регламент предусматривает не только участие Министра промышленности в процессе рассмотрения целесообразности той или иной зарубежной инвестиции канадскую энергетику, но и других федеральных министров, а также возможность обсуждения допуска инвестора в энергетический сектор на уровне федерального правительства. Тем не менее, по словам ряда авторов, такие сложные процедуры допуска зарубежных инвестиций лишь с разрешения министра применяются в

${ }^{5}$ см. подробнее: D.E. Greenfield, P.T. Maguire, Energy (Oil and Gas). Recent Developments, The 2011 Lexpert/American Lawyer Guide to the Leading 500 Lawyers in Canada, Thomson Reuters Canada Limited.

${ }^{6}$ Règlement sur les investissements susceptibles de porter atteinte à la sécurité nationale (examen) (DORS/2009-271) 
исключительных случаях 7 . На сегодняшний день в соответствии с Канадским законом об инвестициях федеральным правительством была приостановлена лишь одна инвестиционная сделка с участием зарубежного капитала ${ }^{8}$.

Инвестирование в канадскую энергетику стимулируется как государством, так и провинциями (чаще всего последними), при этом приоритетным направлением таких мер являются возобновляемые источники энергии. Стимулирование как отечественных, так и зарубежных инвестиций в развитие возобновляемой энергии осуществляется посредством следующих инструментов: (в частности предоставление льготного налогообложения для инвесторов в возобновляемые сферы энергетики, прямые и косвенные субсидии и гранты, а также предоставление льготных тарифов (например, для доступа предприятий, производящих электроэнергию из возобновляемых источников к сетям поставки).

Закон Провинциии Британская Колумбия о чиcmой энергии (Clean Energy Act) ${ }^{9}$ в целях стимулирования инвестиций в сферу возобновляемой энергетики предусматривает создание льготных тарифов для компаний, генерирующих электроэнергию на основе возобновляемых источников энергии (ст. 14 и 15), предоставление субсидий посредством собственного фонда (First Nations Clean Energy Business Fund (Фонд инвестиций в экологически чистую энергию) (ст. 20), а также прямого финансирования (ст. 17.1).

В свою очередь, провинция Альберта в целях стимулирования инвестиций в энергетический сектор предоставляет, так называемые, налоговые кредиты и гранты. Так, налоговые кредиты (The Alberta Development and Research Tax Credit) предоставляются всем инвесторам в передовые энергетические технологии в размере $10 \%$ от общих налоговых выплат. В свою очередь, программа грантов Провинции Альберта (Alberta Innovation Vouchers Program) предусматривает предоставление грантов на развитие технологий в сфере чистой энергетики.

\footnotetext{
${ }^{7}$ D.E. Greenfield, P.T. Maguire, Energy (Oil and Gas). Recent Developments, The 2011 Lexpert/American Lawyer Guide to the Leading 500 Lawyers in Canada, Thomson Reuters Canada Limited.

${ }^{8}$ Loi sur Investissement Canada (L.R.C. (1985), ch. 28 ( $1^{\mathrm{er}}$ suppl.))

${ }^{9}$ Clean Energy Act [SBC 2010] Ch. 22
}

Кроме того, одним из передовых законов, содержащих стимулирующие меры, является Закон провинцุии Онтарио о зеленой энергии и зеленой экономике 2009 г., в рамках которого для производителей ветряной и солнечной энергии предусмотрены льготные тарифы на доступ к сетям.

Закон провинции Онтарио о зеленой энергии и зеленой экономике также устанавливает возможность предоставления кредитов (Ontario Scientific Research and Development Credit Tax) аналогичных существующим в провинции Альберта и применяемым к производителям «чистой» энергии. В частности, для исследований в сфере технологий «чистой» энергии, предоставляются налоговые послабления, позволяющие налогоплательщику сократить выплаты в бюджет на 10\%. Более того, закон предусматривает для инвесторов передовых энергетических технологий налоговые послабления в размере до 20\%, если проекты осуществляются в рамках университетского проекта (Ontario Business-Research Institute Tax Credit).

В рамках Закона провинции Онтарио о зеленой энергии и зеленой экономике Правительством Канады была принята Программа развития восточной части umama (Eastern Ontario Development Program $)^{10}$, которая направлена на софинансирование «зеленых» технологий (в размере до 15\% от общей стоимости того или иного проекта), а также был учрежден Фонд стратегических инвестиицй (Strategic Job and Investment Fund $)^{11}$, который также предоставляет гранты на развитие «чистых» технологий

\section{Соединенные Штаты Америки}

В США не существует крупных федеральных корпораций, а также компаний с доминирующим федеральным участием в сфере энергетики. Исключение сделано лишь в отношении энергетических компаний, принадлежащих местным властям и субъектам федерации.

Наиболее крупной компанией в США, принадлежащей местным органам власти, является Энер-

\footnotetext{
${ }^{10}$ см. подробнее Nicola Bellini, Mike Danson, Henrik Halkie, Regional Development Agencies: The Next Generation?: Networking, Knowledge and Regional Policies, Routledge, 2012.

${ }^{11}$ www.ontariocanada.com/.../ed_sjif_main_en.js; http://www.partnersinprojectgreen.com/ programs/partnerprograms/details/123
} 


\section{Политика и общество 4 (112) • 2014}

гетическая компания Сан-Антонио (City Public Service Energy, San-Antonio (Texas)). Данная компания занимается производством и транспортировкой газа и электричества и принадлежит муниципалитету города Сан-Антонио с 1942 г. ${ }^{12}$

Энергетические рынки США практически полностью либерализованы, т.е. находятся в частной собственности, что является одним из отличий от мексиканской и канадской отрасли энергетики.

В сфере энергетики американские компании, не являются в большей части общефедеральными компаниями, что связано с действующим антимонопольным законодательством ${ }^{13}$.

Так, на субрегиональном уровне была образована одна из таких компаний - Тихоокеанская газовая и электроэнергетическая компания (PG and E Corporation $)^{14}$. Данная компания, как и большинство других энергетических компаний США, является открытым акционерным обществом, которое котируется на Нью-Йоркской фондовой бирже. Как следствие, любое лицо может инвестировать свои средства в акции данной компании, как и других энергетических компаний США.

Следует отметить, что корпоративное право США не является общефедеральным. В каждом штате действует свой свод правил, регулирующих деятельность корпораций, в том числе акционерных обществ ${ }^{15}$.

Тем не менее, на уровне федерации существует несколько модельных законов, а также законов, которые частично применяются в корпоративном праве любого штата, и, соответственно регулируют деятельность всех компаний. В числе таких законов следует назвать Модельный закон о корпоpaųuяx (Model Business Corporation Act) ${ }^{16}$, который был разработан Американской ассоциацией адво-

12 см. подробнее http://www.cpsenergy.com/About_CPS_Energy/Who_We_Are/History/index.asp

${ }^{13}$ Bloomberg, Global Trends in Sustainable Energy Investment 2010: Analysis of Trends and Issues in the Financing of Renewable Energy and Energy Efficiency, UNEP/Earthprint, 2010. -59 p.

${ }^{14}$ www.pgecorp.com

${ }^{15}$ International Buisiness Publications, Us Company Laws and Regulations Handbook Volume 2 Delaware - Corporate Laws and Regulation in the Selected States of the Us Delaware, Int'1 Business Publications, $2009-286$ p.

16 http://users.wfu.edu/palmitar/ICBCorporations-Companion/ Conexus/ModelBusiness CorporationAct.pdf катов (American Bar Association) и который применяется практически в половине штатов ${ }^{17}$.

При этом необходимо отметить, что Общзий корпоративный закон штата Делавэр (Delaware General Corporation Law) ${ }^{18}$ был инкорпорирован во внутреннее право больиинства штатов США ${ }^{19}$.

$B$ сфере инвестирования на федеральном уровне был принят ряд актов, направленных на стимулирование инвестиций посредством обеспечения гарантий прав инвесторов. Одни из них является Закон о иенных бумагах 1933 г. (Securities act) 20 , который обязал корпорации предоставлять инвесторам наиболее полную информацию о финансовых и коммерческих результатах деятельности того или иного предприятия до инвестирования.

Другим актом, также направленным на обеспечение интересов инвесторов и, соответственно, на стимулирование инвестиций посредством обеспечения их безопасности, является принятый в 2002 г. Закон Сарбейнса - Оксли (Sarbanes-Oxley Act) ${ }^{21}$. Данный акт определил правила отчетности и аудита предприятий, ужесточил ответственность корпоративных органов управления, а также установил ответственность за распространение ложной информации о финансовых и коммерческих успехах предприятий. Как следствие, данный акт оказал положительное влияние на инвестиционный климат в США, в том числе на стимулирование инвестирования в энергетические компании.

Основным средством стимулирования инвестиций корпораций в возобновляемые источники энергии на федеральном уровне стал Налоговыц̆ кредит на инвестирование предприятий в энергетику (Business Energy Investment Tax Credit) ${ }^{22}$. Он был установлен Законом о совершенствовании энергетики (Energy Improvement and Extension Act) ${ }^{23}$ в 2008 г. Данный кредит позволяет корпоративным субъектам налогообложения сокращать налоговое

\footnotetext{
${ }^{17}$ K. Kocaoglu, A Comparative Bibliography: Regulatory Competition on Corporate Law. Georgetown University Law Center Working Paper. 2008.

${ }^{18}$ см. подробнее, например: W.A. Klein, J.C. Coffee, Business Organization and Finance,11th ed. Foundation Press, 2010.

${ }^{19} \mathrm{http}: / /$ www.corp.delaware.gov/aboutagency.shtml

${ }^{20} 15$ U.S.C. $-77 \mathrm{a}$

${ }^{21}$ Pub.L. 107-204, 116 Stat. 745, enacted July 30, 2002.

${ }^{22} \mathrm{http}$ ://energy.gov/savings/business-energy-investment-tax-credit-itc

${ }^{23}$ Energy Improvement and Extension Act of 2008 (H.R. 1424)
} 
бремя за счет инвестиций в «чистую» энергетику.

Если стимулирование инвестиций в развитие возобновляемых источников энергии на федеральном уровне является недостаточно развитым, то около сорока штатов Америки на сегодняшний день разработали и имплементировали программы развития альтернативных источников энергии ${ }^{24}$. Основным инструментом такого развития стали «Cтандарты возобновляемой энергии» (Renewable Portfolio Standard), которые, в частности, устанавливают ряд мер по стимулированию инвестиций в возобновляемые источники энергии.

Одним из направлений стимулирования инвестиций в «чистую» энергию являются кредиты возобновляемой энергии (renewable energy credits), которые обязуют того или иного потребителя энергии приобретать определённое количество энергии, произведенной из возобновляемых источников энергии. В случае, если потребитель не может приобрести энергию, произведенную из возобновляемой энергии, ему приходится платить за это ${ }^{25}$.

В отдельных штатах инвестиции в энергетику стимулируются посредством стимулирующих тарифов (feed-in-tariffs), по которым закупается электроэнергия, произведенная из возобновляемых источников. Так в Калифорнии и на Гавайях действуют долгосрочные контракты на поставку «чистой» электроэнергии, позволяющие производителям такой электроэнергии осуществлять гарантированное инвестирование в развитие использования источников возобновляемой энергии ${ }^{26}$.

\section{Мексика}

Закрепление Конституцией Мексики государственной собственности на энергоресурсы (ст. 27) объясняет незначительность объемов частных инвестиций в энергетический сектор. Более того, если либерализация энергетического права в начале - средине 90-х гг., связанная с вступлением Мексики в Североамериканскую зону свободной торговли, позволила частному капиталу инвести-

\footnotetext{
${ }^{24}$ см. подробнее M. B. Gerrard, The Law of Clean Energy: Efficiency and Renewables, 2011.

${ }^{25} \mathrm{http} / / /$ apps3.eere.energy.gov/greenpower/markets/certificates. shtml?page $=0$

${ }^{26}$ см. например OECD, Renewable Energy: Market And Policy Trends In Iea Countries, OECD Publishing, 2004.
}

ровать средства в отдельные сферы энергетики, то нефтегазовая отрасль осталась практически полностью государственной. В соответствии с п. 5 ст. 27 Конституции Мексики: «предоставление концессий на нефть и другие твердые, жидкие и газообразные углеводороды не допускается...». Как уже было сказано, все операции в данном секторе энергетики относятся к государственной монополии, а единственной компанией нефтегазового сектора мексиканской энергетики остается компания Петролиос Мексиканос.

Принимая во внимание тот факт, что компания Петролиос Мексиканос является государственным предприятием, ее финансирование предусматривает предварительное одобрение Министерства финансов Мексики (ст. 44), а предельный уровень финансирования различных операций нефтегазового сектора мексиканской энергетики утверждается Федеральным конгрессом ${ }^{27}$.

В соответствии со ст. 49 она должна ежегодно представлять Министру финансов расчеты бюджета на пятилетнюю перспективу. Более того, в соответствии с п. 6 ст. 49 Закона к инвестиционным проектам компании применяются нормы Федерального закона о бюджете и налоговой отчетноcmu (Ley Federal de Presupuesto y Responsabilidad Hacendaria ${ }^{28}$, в соответствии с которыми инвестиционные проекты требуют одобрения Министерства финансов. Таким образом, инвестирование в мексиканском нефтегазовом секторе энергетики осуществляется государственной компанией с разрешения органов государственной власти.

Аналогичная ситуация сложилась в правовом регулировании сектора атомной энергетики. В соответствии с Законом 1984 г. (Ley Reglamentaria del Artículo 27 Constitucional en Materia Nuclear) ${ }^{29}$ государственная монополия в этой сфере абсолютна, что прямо вытекает из содержания ст. 5 закона. Соответственно, инвестирование данного сектора энергетики осуществляются органами государственной власти.

Приток частного капитала (в том числе, иностранного) в иные энергетические секторы допускается, однако действующее законодатель-

\footnotetext{
${ }^{27}$ Diario Oficial de la Federación el 28 dic. 2008

${ }^{28}$ Diario Oficial de la Federación el 30 de marzo de 2006.

${ }^{29}$ Diario Oficial de la Federación, 4 Feb. 1985.
} 


\section{Политика и общество 4 (112) • 2014}

ство устанавливает ряд ограничений. В первую очередь, следует указать, что Конституция Мексики разграничивает национальные и иностранные инвестиции. В соответствии с ст. 27 Конституции «...только мексиканцы по рождению или натурализации и мексиканские общества имеют право приобретать в собственность земли, воды и все относящееся к ним или получать концессии на эксплуатацию шахт либо вод» ${ }^{30}$. Очевидно, что такое положение Конституции с учетом присоединения Мексики к Североамериканскому соглашению о создании зоны свободной торговли тормозит не только интеграционные процессы в рассматриваемой области общественных отношений, но и развитие энергетического комплекса самой Мексики.

Именно эти причины обусловили либерализацию инвестиций в мексиканскую энергетику. Так, например, незадолго до создания Североамериканской зоны свободной торговли в 1993 г. был принят акт, позволивший зарубежным инвесторам заниматься геологической разведкой и добычей угля - Закон об иностранных инвестициях (Ley de Inversión Extranjera) ${ }^{31}$. В результате были отменены такие дискриминирующие положения мексиканского законодательства, как ограничение доли иностранного участия в уставном капитале энергетических компаний в $49 \%$ уставного капитала.

Однако ряд ограничений в отношении зарубежных инвестийий сохранился. Основным из них является письменный отказ иностранных инвесторов от дипломатической зашиты их государства, который представляется в Министерство иностранных дел Мексики и является одним из обязательных условий их допуска в энергетический сектор Мексики. Другим примером может служить запрет допуска иностранных инвесторов в деятельность по разведке и добыче, осуществляемую в стокилометровой приграничной зоне ${ }^{32}$. В ито-

30 См. Конституция Мексики. // Конституции государств Америки: В трех томах / Под ред. Т.Я. Хабриевой. Т.1 - М.: Институт законодательства и сравнительного правоведения при Правительстве Российской Федерации, 2006.С. 478.

${ }^{31}$ Diario Oficial de la Federación, 29 Mar 1993

32 J. Selivanova, Regulation of Energy in International Trade Law: WTO, NAFTA and Energy Charter, Kluwer Law International, 2011 ге можно сделать вывод о том, что на сегоднямний день зарубежным инвесторам предоставляется национальный режим в области добычи угля $и$ электроэнергетики.

Ст. 5 Закона устанавливает прямой запрет на передачу частным предприятиям кониессию на добычу полезных ископаемых, устанавливая в тоже время ряд исключений. Данное положение запрещзает передачу кониессий (частным предприятиям) на добычу углеводородов (нефти и газа), а также радиоактивных руд, что логически ограничивает участие частного капитала в разведке и добыче ископаемых энергоресурсов лишь углем.

Лица, которым предоставлена концессия, обязаны платить за каждый гектар земли, предоставленной им в концессию, от 5,08 до 111,17 мексиканских песо раз в иесть месяиев ${ }^{33}$.

Концессионер имеет право на свободную передачу вверенной ему концессии (в том числе на возмездной основе) и может затребовать у нового пользователя выплату роялти (royalties). В целях осуществления контроля со стороны государства и третьих лиц все соглашения на передачу концессий от концессионера третьим лицам регистрируются в государственном регистре горнодобывающей промышленности.

\section{Библиография:}

1. F. P. Sioshansi, W. Pfaffenberger, Electricity Market Reform: An International Perspective, Elsevier, 2006.-688 p.

2. D.E. Greenfield, P.T. Maguire, Energy (Oil and Gas). Recent Developments, The 2011 Lexpert/ American Lawyer Guide to the Leading 500 Lawyers in Canada, Thomson Reuters Canada Limited.

3. Nicola Bellini, Mike Danson, Henrik Halkie, Regional Development Agencies: The Next Generation?: Networking, Knowledge and Regional Policies, Routledge, 2012.

4. K. Kocaoglu, A Comparative Bibliography: Regulatory Competition on Corporate Law. Georgetown University Law Center Working Paper. 2008 .

33 A. Johnson, Mexico Tax, Law and Business Briefing, WorldTrade Executive, Inc., 2005 - 
5. W.A. Klein, J.C. Coffee, Business Organization and Finance, 11th ed. Foundation Press, 2010.

6. M. B. Gerrard, The Law of Clean Energy: Efficiency and Renewables, 2011.

7. Конституция Мексики. // Конституции государств Америки: В трех томах / Под ред. Т.Я. Хабриевой. Т.1 - М.: Институт законодательства и сравнительного правоведения при Правительстве Российской Федерации, 2006.С. 478.

8. J. Selivanova, Regulation of Energy in International Trade Law: WTO, NAFTA and Energy Charter, Kluwer Law International, 2011

9. A. Johnson, Mexico Tax, Law and Business Briefing, WorldTrade Executive, Inc., 2005

10. Курбанов Р.А. Структура энергетического сектора и вопросы международно-правового регулирования энергетики Североамериканских государств // NB: Международное право. - 2013. - 4. - C. 201-228. DOI: 10.7256/23069899.2013.4.11026. URL: http://www.enotabene.ru/wl/article_11026.html

11. Ожогин В.Б. Государственное регулирование институциональной инвестиционной среды // Национальная безопасность / nota bene. - 2013. - 5. - C. 156-172. DOI: 10.7256/20738560.2013 .5 .9615 .

12. С.О. Шемшученко Двусторонние инвестиционные соглашения: типичная структура, понятия и формулировки положений // Право и политика. - 2012. - 12. - С. 2030-2034.

13. Ксенофонтов К.Е. Допустимость экспроприации собственности иностранного инвестора принимающим государством // Международное право и международные организации / International Law and International Organizations. - 2013. - 3. - C. 323-329. DOI: 10.7256/22266305.2013.3.9706.

14. А. А. Данельян. Роль международных организаций в регулировании международных экономических отношений: опыт, современные проблемы и тенденции. // Международное право и международные организации / International Law and International Organizations. - 2012. - № 3. - C. 116-123.

15. И.М.Соколов.Эффективностьгосударственных решений в условиях модернизации: опыт стран мира. // Тренды и управление. - 2013. - № 2. C. 227-235. DOI: .10.7256/2307-9118.2013.2.495

\section{References (transliteration):}

1. F. P. Sioshansi, W. Pfaffenberger, Electricity Market Reform: An International Perspective, Elsevier, 2006. - 688 r.

2. D.E. Greenfield, P.T. Maguire, Energy (Oil and Gas). Recent Developments, The 2011 Lexpert/ American Lawyer Guide to the Leading 500 Lawyers in Canada, Thomson Reuters Canada Limited.

3. Nicola Bellini, Mike Danson, Henrik Halkie, Regional Development Agencies: The Next Generation?: Networking, Knowledge and Regional Policies, Routledge, 2012.

4. K. Kocaoglu, A Comparative Bibliography: Regulatory Competition on Corporate Law. Georgetown University Law Center Working Paper. 2008.

5. W.A. Klein, J.C. Coffee, Business Organization and Finance, 11 th ed. Foundation Press, 2010.

6. M. B. Gerrard, The Law of Clean Energy: Efficiency and Renewables, 2011.

7. J. Selivanova, Regulation of Energy in International Trade Law: WTO, NAFTA and Energy Charter, Kluwer Law International, 2011

8. A. Johnson, Mexico Tax, Law and Business Briefing, WorldTrade Executive, Inc., 2005

9. Kurbanov R.A. Struktura energeticheskogo sektora i voprosy mezhdunarodno-pravovogo regulirovaniya energetiki Severoamerikanskikh gosudarstv // NB: Mezhdunarodnoe pravo. - 2013. - 4. - C. 201-228. DOI: 10.7256/2306-9899.2013.4.11026. URL: http://www.e-notabene.ru/wl/article_11026. html

10. Ozhogin V.B. Gosudarstvennoe regulirovanie institutsional'noi investitsionnoi sredy // Natsional'naya bezopasnost' / nota bene. 2013. - 5. - C. 156-172. DOI: 10.7256/20738560.2013.5.9615.

11. S.O. Shemshuchenko Dvustoronnie investitsionnye soglasheniya: tipichnaya struktura, ponyatiya i formulirovki polozhenii // Pravo i politika. - 2012. - 12. - C. 2030-2034.

12. Ksenofontov K.E. Dopustimost' ekspropriatsii sobstvennosti inostrannogo investora prinimayushchim gosudarstvom // Mezhdunarodnoe pravo i mezhdunarodnye organizatsii / Interna- 
DOI: $10.7256 / 1812-8696.2014 .4 .11630$

При цитировании этой статьи сноска на dоі обязательна

\section{Политика и общество 4 (112) • 2014}

tional Law and International Organizations. 2013. - 3. - C. 323-329. DOI: 10.7256/22266305.2013.3.9706.

13. A. A. Danel'yan. Rol' mezhdunarodnykh organizatsii $v$ regulirovanii mezhdunarodnykh ekonomicheskikh otnoshenii: opyt, sovremennye problemy i tendentsii. // Mezhdunarodnoe pra- vo i mezhdunarodnye organizatsii / International Law and International Organizations. - 2012. - № 3. - C. 116-123.

14. I.M. Sokolov. Effektivnost' gosudarstvennykh reshenii v usloviyakh modernizatsii: opyt stran mira. // Trendy i upravlenie. - 2013. - № 2. - C. 227-235. DOI: .10.7256/2307-9118.2013.2.495 